\title{
AgO investigated by photoelectron spectroscopy: Evidence for mixed valence
}

\author{
M. Bielmann, ${ }^{1}$ P. Schwaller, ${ }^{2}$ P. Ruffieux, ${ }^{1}$ O. Gröning, ${ }^{2}$ L. Schlapbach, ${ }^{1}$ and P. Gröning ${ }^{1}$ \\ ${ }^{1}$ Physics Department, University of Fribourg, Pérolles, CH-1700 Fribourg, Switzerland \\ ${ }^{2}$ Materials Technology Department EMPA Thun, Feuerwerkerstrasse 39, CH-3602 Thun, Switzerland
}

(Received 18 February 2002; published 20 June 2002)

\begin{abstract}
We present photoelectron spectroscopy investigations of in-situ prepared AgO. The sample was prepared by room temperature oxidation of $\mathrm{Ag}$ in an electron cyclotron resonance $\mathrm{O}_{2}$ plasma. In contrast to other measurements based on ex situ prepared AgO powder samples, our investigations show a distinct double peak structure of the $\mathrm{O} 1 \mathrm{~s}$ signal with a remarkable chemical shift of $2.9 \mathrm{eV}$ between the two $\mathrm{O} 1 s$ components. These two components can not be motivated from a crystallographic point of view as the oxygen sites are all equivalent in the unit cell. We interpret this double peak structure as a characteristic feature of AgO and discuss it in terms of mixed valences.
\end{abstract}

DOI: 10.1103/PhysRevB.65.235431

\section{INTRODUCTION}

Silver oxides have been extensively studied in the past due to their high importance in numerous technical applications. For example, the interaction of silver surfaces with oxygen plays a key role for the silver-catalyzed epoxidation of ethylene ${ }^{1}$ and the partial oxidation of methanol to formaldehyde. ${ }^{2}$ Silver partially oxidizes the reactants instead of producing pure combustion products. Therefore a detailed knowledge of silver oxide surfaces is important for the understanding of catalytical phenomena. Photoelectron spectroscopy (PES) has proven to be an important tool to study silver oxide surfaces. There exists a wide variety of PES data for the two silver oxides $\mathrm{AgO}$ and $\mathrm{Ag}_{2} \mathrm{O}$, dating back as far as to the early days of PES. ${ }^{3-9}$ In the literature, theoretical work on the topic can also be found. ${ }^{10-12}$

$\mathrm{AgO}$ has a monoclinic structure [Fig. 1(a)] containing two inequivalent silver sites. Ag I is twofold coordinated by oxygen while Ag III is fourfold coordinated by $\mathrm{O}$ atoms. All oxygen sites are equivalent. $\mathrm{AgO}$ is an $n$-type semiconductor. ${ }^{15} \mathrm{Ag}_{2} \mathrm{O}$ [Fig. 1(b)] is cubic with six atoms per unit cell. The oxygen atoms form a bec lattice and are tetrahedrally coordinated by $\mathrm{Ag}$ atoms. The bonding in $\mathrm{Ag}_{2} \mathrm{O}$ is primarily ionic with $\mathrm{Ag}^{+}$and $\mathrm{O}^{2-}$ valences ${ }^{11}$ making $\mathrm{Ag}_{2} \mathrm{O}$ an insulator with an electronic gap of $1 \mathrm{eV}$ (Ref. 7) as observed by UPS. Much work has been devoted to the investigation of silver oxides, however the identification of the oxygen species from PES spectra remains controversial. To some extent this is due to the fact that many groups base their measurements on powder samples transferred to ultrahigh vacuum (UHV) conditions. ${ }^{3,8,9}$ Contaminations due to the contact with ambient atmosphere lead to additional oxygen species, complicating the interpretation considerably. Furthermore, $\mathrm{AgO}$ is an unstable oxide: it starts to decompose over $100^{\circ} \mathrm{C}$ into $\mathrm{Ag}_{2} \mathrm{O}$ which itself decomposes above $300^{\circ} \mathrm{C}$. ${ }^{9}$ For $\mathrm{Ag}_{2} \mathrm{O}$, Tjeng et al. ${ }^{7}$ presented an in situ preparation method based on a free radical oxygen source. From their work it is obvious that the elimination of contributions from surface contaminations facilitates the interpretation of the spectra. Farhat et al. ${ }^{14-16}$ produced AgO by $\mathrm{O}_{2}$ plasma treatment of Ag films evaporated on quarz crystal microbalance (QCM) crystals, but no measurements of the oxide with PES were performed. The role of the plasma is primarily to
PACS number(s): 81.65.Mq, 82.33.Xj, 82.80.Pv

bypass the dissociative adsorption step. It has been shown by Outlaw et al. ${ }^{17}$ that oxygen diffusion into the bulk can be increased by more than an order of magnitude if the gas is dissociated in a plasma. In this paper we will, to our knowledge for the first time, present PES data of in situ prepared $\mathrm{AgO}$ by room temperature oxidation in an electron cyclotron resonance (ECR) $\mathrm{O}_{2}$ plasma. The measurements reveal a distinct double peak structure in the $\mathrm{O} 1 \mathrm{~s}$ signal, which we relate to a mixed valency on the oxygen sites.

\section{EXPERIMENT}

All experiments were performed in a modified Omicron photoelectron spectrometer equipped with an EA $125 \mathrm{HR}$ electron analyzer and an electron cyclotron resonance (ECR) plasma chamber with $2.45 \mathrm{GHz}$ microwave source. The base pressure of the system is $5 \times 10^{-11}$ mbar. Untreated $\mathrm{Ag}$ single crystal surfaces and plasma-treated surfaces were investigated by low-energy electron diffraction (LEED), $x$-ray photoelectron spectroscopy (XPS), and ultraviolet photoelectron spectroscopy (UPS). As photon sources we used nonmonochromatized $\mathrm{Mg} \mathrm{K} \alpha$ x rays $(1253.6 \mathrm{eV})$, monochromatized $\mathrm{Al} \mathrm{K} \alpha \mathrm{x}$ rays $(1486.6 \mathrm{eV})$, and $\mathrm{He} \mathrm{I}$ radiation $(21.2 \mathrm{eV})$ from a gas discharge lamp. The spectrometer is calibrated to a $\mathrm{Au} 4 f_{7 / 2}$ binding energy (BE) of $83.8 \mathrm{eV}$. AgO was produced by an ECR $\mathrm{O}_{2}$ plasma. Prior to oxidation, $\mathrm{Ag}$ single crystal surfaces where sputtered with $1.5 \mathrm{keV} \mathrm{Ar}{ }^{+}$ions and annealed at $\sim 800 \mathrm{~K}$ until a sharp LEED pattern was obtained and no $\mathrm{C}$ or $\mathrm{O}$ contaminations could be observed by XPS. The oxidation step was performed applying an $\mathrm{O}_{2}$ ECR a)

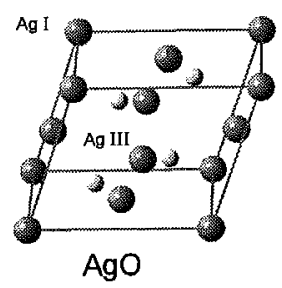

b)

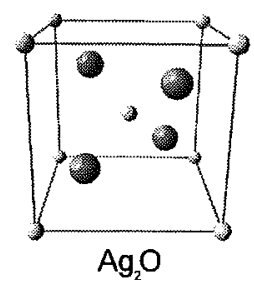
13).

FIG. 1. Unit cells of the $\mathrm{AgO}$ and $\mathrm{Ag}_{2} \mathrm{O}$ crystal structure (Ref. 
plasma during $30 \mathrm{~min}$. The gas pressure during the treatment was $3 \times 10^{-2}$ mbar and the sample was set to ground potential.

The major difference between oxidation under gas flow at elevated temperatures and a ECR plasma treatment is the presence of atomic, excited and ionized atomic species in the plasma. Further, the bulk sample is at RT, but the kinetic energy of the ions striking the surface leads to a local heating of the surface..$^{2,23}$ The operation pressure of ECR plasmas is $10^{-4}-10^{-1}$ mbar. In this pressure range, the electrons and heavy species in the plasma are not in thermodynamical equilibrium, even on a scale in the order of the Debye length $\lambda_{D}(\sim 0.1 \mathrm{~mm})$. In such low pressure plasmas the electron temperature $T_{e}$ is in the range of $\mathrm{eV}$ while the temperatures of the heavy species (ions, neutrals) are all in the order of kT $(\sim 25 \mathrm{meV})$. Therefore such plasmas are generally referred to as cold plasmas. ${ }^{18}$ Though the ion temperature $T_{\text {ions }}$ is room temperature (RT), a sample inserted into a cold plasma will be struck by ions with a kinetic energy of a few $\mathrm{eV}$. This is due to the fact that a plasma is always positively charged. The excess ions caused by the higher recombination rate of the highly mobile electrons at the container walls compared to the heavy ions $\left(\left\langle v_{e}\right\rangle \gg\left\langle v_{\text {ions }}\right\rangle \leftrightarrow T_{e} \gg T_{\text {ions }}\right)$ gives rise to the so-called plasma potential. This plasma potential defines the kinetic energy with which the ions strike the surface ${ }^{19}$ and depends on the type of plasma as well as the geometry of the setup. Such variations in design can lead to a distinctly different composition of the plasma. ${ }^{18,19}$ For our setup, the ion current density is $25 \mathrm{nA} / \mathrm{mm}^{2}$ and the average $O$ ion energy is about $4 \mathrm{eV}$ for the given parameters as measured by an electrostatic ion energy analyzer. ${ }^{20}$

\section{RESULTS AND INTERPRETATION}

\section{A. Quartz crystal microbalance}

A $50 \mathrm{~nm} \mathrm{Ag} \mathrm{film} \mathrm{evaporated} \mathrm{in} \mathrm{situ} \mathrm{on} \mathrm{a} \mathrm{QCM} \mathrm{crystal} \mathrm{was}$ exposed to the $\mathrm{O}_{2}$ plasma under identical conditions as the Ag single crystals. The mass uptake during oxidation can be calculated from the dynamically measured change in resonance frequency of the vibrating microbalance crystal. The resulting $\mathrm{O} / \mathrm{Ag}$ ratio is presented in Fig. 2. After $30 \mathrm{~min}$ of oxidation, the $\mathrm{O} / \mathrm{Ag}$ ratio is 1.05 and therefore an oxidation time of $30 \mathrm{~min}$ on the single crystal surfaces was applied. Under the used conditions, AgO layers with well over $1 \mu \mathrm{m}$ thickness can be prepared. During the plasma treatment, the film changed its color from silver to golden/brownish followed by a dark gray appearance. The brownish color is generally associated with $\mathrm{Ag}_{2} \mathrm{O}$, while the dark gray color is associated with $\mathrm{AgO} .^{21}$ The same phenomena in color change could also be observed on the single crystal surfaces.

\section{B. X-ray photoelectron spectroscopy}

Experiments presented in the following were performed on $\operatorname{Ag}(110)$, the most open surface of the low index silver planes. Measurements on the (111) surface revealed identical results in XPS and are therefore not presented. The Ag $3 d_{5 / 2}$ spectra for the clean and the oxidized sample measured with monochromatized $\mathrm{Al} K \alpha$, are shown in Fig. 3(a). The corresponding peak positions and peak widths are resumed in

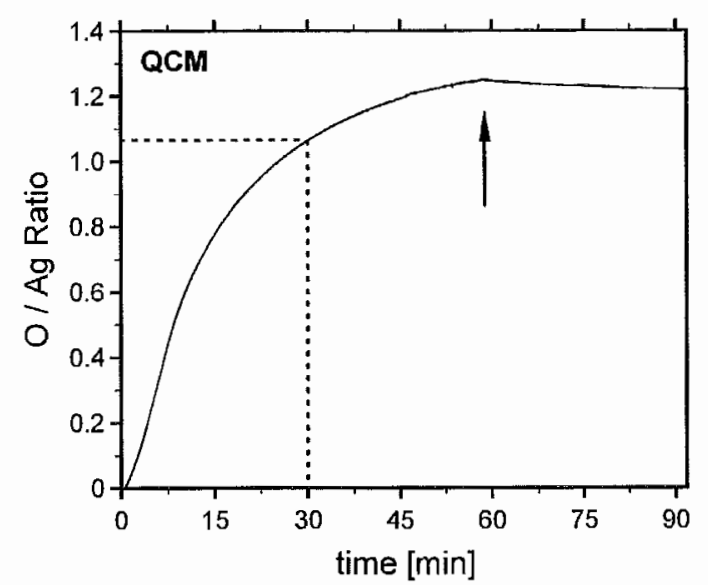

FIG. 2. O/Ag ratio during oxidation of a $50 \mathrm{~nm} \mathrm{Ag} \mathrm{film} \mathrm{evapo-}$ rated on a QCM crystal with gold electrodes. The O/Ag ratio is about 1.05 after $30 \mathrm{~min}$, underlining the conclusion of AgO formation. The arrow indicates the point where the plasma was switched off.

Table I. Figure 3(b) shows the $\mathrm{O} 1 s$ spectra after oxidation, exhibiting two distinct components. The lower BE component is centered at $528.6 \mathrm{eV}$ with a FWHM of $0.9 \mathrm{eV}$. The higher BE component is centered at $531.5 \mathrm{eV}$ with a FWHM of $1.3 \mathrm{eV}$.

This second peak was not observed by Tjeng et al. ${ }^{7}$ on $\mathrm{Ag}_{2} \mathrm{O}$. Their spectra exhibit a single $\mathrm{O} 1 s$ signal, at a $\mathrm{BE}$ of $528.9 \mathrm{eV}$. For shorter plasma exposure times, where we assume that predominantly $\mathrm{Ag}_{2} \mathrm{O}$ is present, we observe the same $\mathrm{O} 1 \mathrm{~s}$ signal as Tjeng et $a l^{7}$ denoted in Table I. But with ongoing oxidation, the lower BE component shifts further down to $528.6 \mathrm{eV}$ and the initially small but present

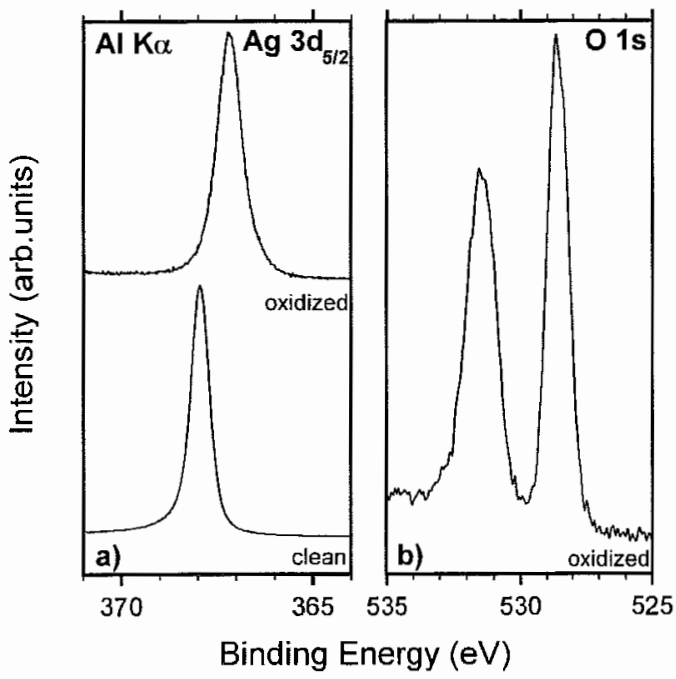

FIG. 3. $\mathrm{Ag} 3 d_{5 / 2}$ and $\mathrm{O} 1 \mathrm{~s}$ signals of clean and oxidized $\mathrm{Ag}(110)$ by ECR plasma as measured by XPS with monochromatized $\mathrm{Al} K \alpha$ radiation. (a) $\mathrm{Ag} 3 d_{5 / 2}$ signal: the oxidized surface shows a peak shift of $-0.8 \mathrm{eV}$ from 368.0 to $367.2 \mathrm{eV}$ and a broadening of 0.2 to $0.76 \mathrm{eV}$ compared to the sputtered and annealed sample. (b) $\mathrm{O} 1 s$ signal: The double peak structure comprises a lower BE component at $528.6 \mathrm{eV}$ with a FWHM of $0.9 \mathrm{eV}$ and a higher $\mathrm{BE}$ component of equal intensity at $531.5 \mathrm{eV}$ with a FWHM of $1.3 \mathrm{eV}$. 
TABLE I. Binding energies and peak widths of $\mathrm{Ag} 3 d_{5 / 2}$ and $\mathrm{O}$ $1 s$ signals as measured with monochromatized Al $K \alpha$. Values denoted by an asterisk are taken from Tjeng et al. (Ref. 7) and were measured with nonmonochromatized $\mathrm{Al} K \alpha$.

\begin{tabular}{lccc}
\hline \hline compound & electron level & $\mathrm{BE}[\mathrm{eV}]$ & FWHM $[\mathrm{eV}]$ \\
\hline $\mathrm{Ag}$ & $\mathrm{Ag} 3 d_{5 / 2}$ & 368.0 & 0.57 \\
$\mathrm{AgO}$ & $\mathrm{Ag} 3 d_{5 / 2}$ & 367.2 & 0.76 \\
& $\mathrm{O} 1 s$ & 528.6 & 0.9 \\
& $\mathrm{O} 1 s$ & 531.5 & 1.3 \\
$\mathrm{Ag}_{2} \mathrm{O}^{*}$ & $\mathrm{Ag} 3 d_{5 / 2}$ & 367.6 & \\
& $\mathrm{O} 1 \mathrm{~s}$ & 528.9 & 1.2 \\
\hline \hline
\end{tabular}

higher BE component grows in intensity until the peak integral of both components are equal. Quantitative analysis of the $\mathrm{Ag}$ and $\mathrm{O}$ peak intensities taking into account cross sections ${ }^{24}$ and analyzer transmission ${ }^{25}$ yields an $\mathrm{O} / \mathrm{Ag}$ ratio of $1.0 \pm 0.1$ which perfectly matches the comparative measurement of the evaporated Ag film on the QCM presented above. Grazing angle measurements show little difference in the intensity between the two components as compared to normal emission after complete oxidation. The investigated $\mathrm{AgO}$ surface is therefore at least homogeneous within the analysis depth of XPS $(\sim 5 \mathrm{~nm})$. We understand the double peak $\mathrm{O} 1 s$ structure with a chemical shift of $2.9 \mathrm{eV}$ as a characteristic feature of $\mathrm{AgO}$.

The oxidation reaction by ECR plasma treatment differs from the reaction caused by a free radical source as used by Tjeng et al. ${ }^{7}$ due to the presence of ions in the ECR plasma. Therefore, the presence of the ions is a necessity for producing $\mathrm{AgO}$. We would like to stress that no traces of $\mathrm{C}$ where measured, excluding therefore contributions to the oxygen signal from $\mathrm{CO}$ species. An identical chemical shift between two $\mathrm{O} 1 s$ components as in our measurements was observed by Boronin $e t a l^{27}$ In their work, they interpret the higher $\mathrm{BE}$ component to be due to adsorption of exited oxygen species from the plasma on the $\mathrm{Ag}_{2} \mathrm{O}$ surface. They understand this peak as a adsorbate species because it vanishes by dosing the surface with $10^{8} \mathrm{~L}$ of ethylene at $125^{\circ} \mathrm{C}$. However, Tanaka $e t a l{ }^{26}$ have shown by TDS experiments that dosing of $\mathrm{AgO}$ with ethylene leads to a bulk reduction of $\mathrm{AgO}$ to $\mathrm{Ag}_{2} \mathrm{O}$. Furthermore, over $100^{\circ} \mathrm{C} \mathrm{AgO}$ starts to decompose into $\mathrm{Ag}_{2} \mathrm{O}$. Therefore, the loss of the higher $\mathrm{BE}$ component might as well be due to a reduction of a bulk oxide species different from $\mathrm{Ag}_{2} \mathrm{O}$. As revealed by grazing angle measurements, we can safely exclude in our case that the higher binding energy component is due to adsorbed oxygen at the surface. We further exclude that the higher BE O $1 s$ component is due to a mixture of atomic subsurface oxygen and hydroxyl groups as suggested by Weaver $e t$ al. ${ }^{9}$ and Hoflund et al. ${ }^{8}$ For early stages of the oxidation the lower $\mathrm{BE}$ component dominates the spectra. If the higher BE O $1 s$ component arises from hydroxyl groups, one would expect that this peak dominates the spectra in an initial phase as the hydrogen content is highest after ignition of the plasma due to desorption of the chamber walls and gas system. Subsurface contributions should be build up before oxygen diffuses into the bulk and would therefore lead to a dominant higher
BE component for lower plasma exposure times. This is in contradiction to our observations.

As mentioned above, the oxygen sites in $\mathrm{AgO}$ are structurally equivalent and therefore the two peaks cannot be explained from different local structures. In a theoretical work on AgO of Park et al. ${ }^{10}$ it is suggested, that a large number of holes exist on the oxygen sites. They suggest that silver is present as $\mathrm{Ag}^{+}$and $\mathrm{Ag}^{2+}$ valences rather than as $\mathrm{Ag}^{+}$and $\mathrm{Ag}^{3+}$ and consequently, there must exist an considerable amount of oxygen with -1 valency. In a charge transfer model, a negative peak shift in BE for the element with higher electronegativity is expected. For most oxides, the oxygen $\mathrm{BE}$ shows a negative peak shift compared to the $\mathrm{BE}$ of the free molecule. The shift scales with the valency of the oxygen. In $\mathrm{Ag}_{2} \mathrm{O}$ the oxygen atom is present as $\mathrm{O}^{2-}$. As seen in the measurements of Tjeng $\mathrm{et} \mathrm{al.}{ }^{7}$ an atom in this configuration shows a BE around $529 \mathrm{eV}$. As the lower BE O 1 s component of our measurements lies close to $529 \mathrm{eV}$, we understand this peak to reflect essentially a -2 valency. The higher BE $\mathrm{O} 1 s$ component at $531.5 \mathrm{eV}$ shows a remarkably smaller shift and a distinct broadening compared to the free molecule and therefore the charge transfer, respectively, the valency must be different. For $\mathrm{O}^{-}$, such a behavior is expected. The increased peak width indicates a significantly shorter lifetime of the particular state.

Mixed valences can be understood as the fluctuation of the valence state of an atom, e.g., where a valence electron hops between neighboring atoms. Separate binding energy peaks are therefore possible for atoms with different oxidation states in structurally equivalent sites. ${ }^{28}$ Kohn et al. ${ }^{29}$ have theoretically shown, that the observation of the phenomena is not related to the characteristic time of the photoemission process. They showed that a double peak structure can be observed for $U \gg V$ where $U$ is the interaction energy of the electrons on the same nucleus and $V$ is a coupling energy describing the transition between the two electronic configurations. Detailed theoretical discussion of the phenomena can be found in the given reference. We understand the presented results as the manifestation of a $-1 /-2$ valency fluctuation on the structurally equivalent $O$ sites. As the electrostatic screening of the other electrons in $\mathrm{Ag}$ is considerably higher, the manifestation of the mixed valency as resolvable peaks on the localized $4 d$ levels of $\mathrm{Ag}$ cannot be expected with the present setup. It rather manifests itself as a broadening of the signal which cannot be resolved from the broadening due to signal components which arise from different local structures around the inequivalent $\mathrm{Ag}$ sites.

\section{Ultraviolet photoelectron spectroscopy}

Figure 4 shows the UPS spectra measured in normal emission (i.e., at the $\Gamma$ point) for clean $\operatorname{Ag}(110)$ and after 30 min of oxidation. (Note, that the produced oxide is not a single crystal.) Figure 4(b) shows the region around $E_{F}$. For $\mathrm{Ag}_{2} \mathrm{O}$ an electronic gap of $1 \mathrm{eV}$ was found by Tjeng et al. ${ }^{7}$ We find a gap of $1.09 \mathrm{eV}$ for an intermediate oxidation step while for long oxidations a gap of $0.52 \mathrm{eV}$ was found. We define the gap as the intersection of a linear fit in the background region before the gap and in the edge of the occupied states to $E_{F}$. The closing of the gap with ongoing oxidation 


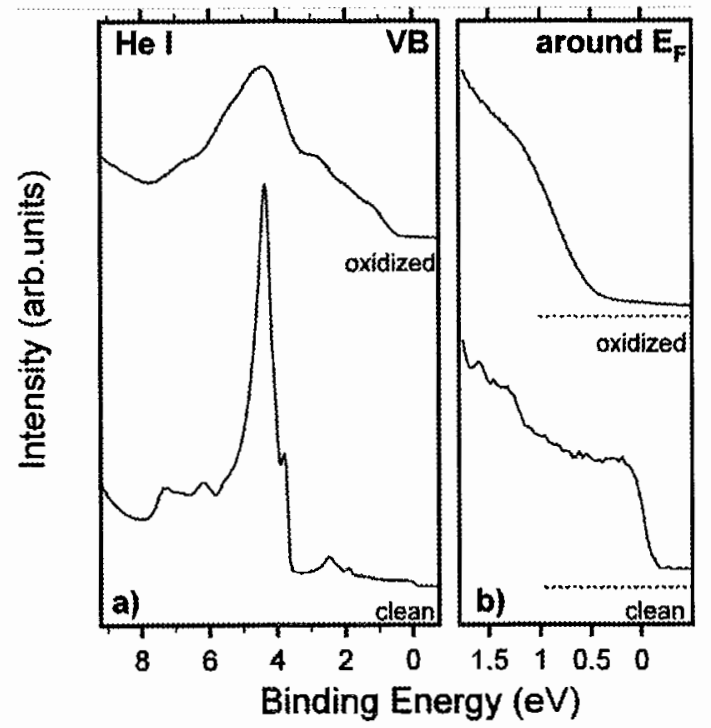

FIG. 4. Valence band spectra measured with HeI radiation at normal emission. (a) Clean and oxidized $\operatorname{Ag}(110)$ surface. (b) Shows the Fermi edges for the corresponding measurements. The top of the valenceband of the oxidized sample is located $0.52 \mathrm{eV}$ below the Fermi level.

corroborates the assumption of oxygen acting as a dopant, as suggested in the model by Park et al. ${ }^{10}$

\section{Stability}

The question of stability of AgO surfaces was addressed by exposing them for prolonged periods to UHV conditions, to ambient atmosphere and to $x$-ray radiation. These experiments where motivated to understand the behavior of the produced surface exposed to conditions comparable to $\mathrm{AgO}$ powder samples transferred to UHV conditions.

After $20 \mathrm{~h}$ in UHV at RT, the surface did not show any variations in composition and therefore can be considered stable in UHV for our measurements. The results after contact to ambient atmosphere are presented in Figs. 5(a) (XPS) and 5(b) (UPS). The higher BE O $1 s$ component is strongly reduced while $\mathrm{C}$ contaminations lead to multiple $\mathrm{O} 1 \mathrm{~s}$ components around $529.5 \mathrm{eV}$ similar to the ones seen by Hoflund et al. ${ }^{8}$ indicated by a broad, gray shaded peak in Fig. 5(a). Along with the reduction of the higher BE O $1 s$ signal, also a shift of the lower BE signal to higher BE is observed. The respective UPS spectra shown in the Fig. 5(b) reveal an opening of the gap by 0.2 to $0.72 \mathrm{eV}$. Such a behavior is expected for the surface decomposition of $\mathrm{AgO}$ into $\mathrm{Ag}_{2} \mathrm{O}$, the more stable and insulating oxide due to contact with air. These findings lead us to the assumption that $\mathrm{AgO}$ powder samples exposed to air already decompose at the surface before any measurement can be performed. Therefore, even if the bulk sample is still $\mathrm{AgO}$ in nature, the near surface region within the analysis depth of PES is altered in a way that the gained data are not characteristic for the system. Also, the always present carbon contaminations in powder samples lead to additional $\mathrm{O} 1 s$ contributions, making interpretation of the results a very difficult and ambiguous task. $\mathrm{Ar}^{+}$sputtering does not recover the original $\mathrm{AgO}$ surface as the sput-

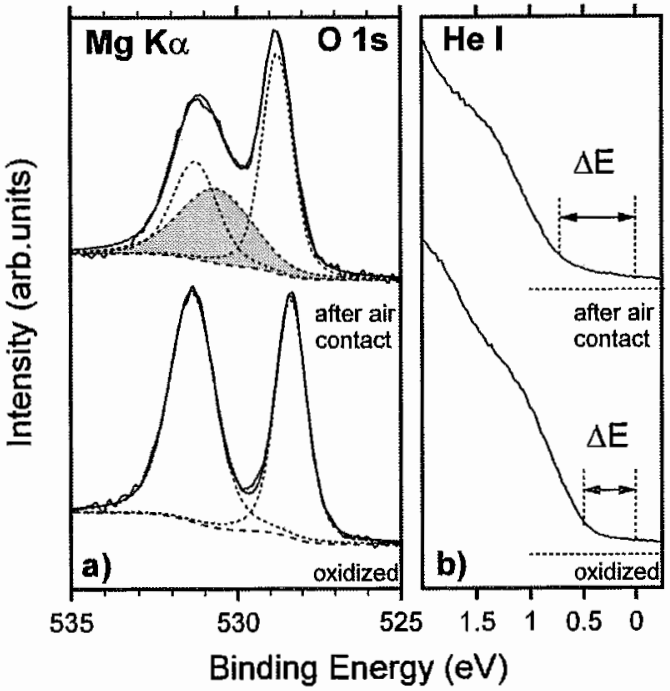

FIG. 5. O $1 s$ signal of a oxidized $1 \mu \mathrm{m} \mathrm{Ag}$ film on Au. (a) O $1 s$ XPS spectra after oxidation and exposure to ambient atmosphere for $17 \mathrm{~h}$. (b) Respective UPS spectra around $E_{F}$. The gray shaded area indicates contributions from carbon contaminations. The gap in the UPS spectra increases from 0.5 to $0.72 \mathrm{eV}$ after the contact with air.

tering process itself leads to decomposition of $\mathrm{AgO}$. We observed a degeneration of the oxide under long term $\mathrm{x}$-ray exposure $(P=240 \mathrm{~W})$. The higher $\mathrm{BE}$ signal decreased about $10 \%$ compared to the lower binding energy component after $7 \mathrm{~h}$ of $\mathrm{x}$-ray exposure. As such a behavior can be observed also with the monochromatic source it is clearly not only related to IR radiation of the x-ray source. The elimination of the higher $\mathrm{BE}$ peak indicates a decomposition to the more stable $\mathrm{Ag}_{2} \mathrm{O}$. As our measurements do not demand such extensive radiation exposure, the presented results are not affected by stability issues. Nevertheless, one needs to be aware that PES measurements on AgO can be affected by radiation exposure and demand an in situ preparation of the oxide.

\section{DISCUSSION AND SUMMARY}

In this work, we presented PES data of in situ prepared AgO by ECR plasma treatment at room temperature. To our knowledge, there are no comparable measurements in literature based on in situ prepared AgO. The PES spectra exhibit a double peak structure with an BE difference of $2.9 \mathrm{eV}$. We interpret this double peak structure as a characteristic feature of $\mathrm{AgO}$ due to a mixed valence state of the structurally equivalent oxygen atoms. Park et al. ${ }^{10}$ suggested that $\mathrm{Ag}$ atoms are present in $\mathrm{ag}^{+}$and $\mathrm{Ag}^{2+}$ valency rather than $\mathrm{Ag}^{+}$ and $\mathrm{Ag}^{3+}$ as a consequence of $e^{-}$holes on the oxygen sites. Therefore, there exist oxygen sites which do exhibit -1 and -2 valences and our measurements do represent this two component.

\section{ACKNOWLEDGMENTS}

Skillful technical assistance was provided by R. Schmid, E. Mooser, O. Raetzo, Ch. Neururer, and F. Bourqui. This work was supported by the Swiss National Science Foundation. 
${ }^{1}$ R.A. Van Santen and H.P.C.E. Kuipers, Adv. Catal. 35, 265 (1987).

${ }^{2}$ A.J. Nagy, G. Mestl, and R. Schlögl, J. Low Temp. Phys. 188, 58 (1999).

${ }^{3}$ G. Schön, Acta Chem. Scand. 27, 2623 (1973).

${ }^{4}$ J.S. Hammond, S.W. Gaarestroom, and N. Winograd, Anal. Chem. 47, 2193 (1975).

${ }^{5}$ R.C. Ross, R. Sherman, and R.A. Bunger, Sol. Energy Mater. 19, 55 (1989).

${ }^{6}$ M. Bowker, Surf. Sci. Lett. 155, L276 (1985).

${ }^{7}$ L.H. Tjeng, M.B.J. Meinders, J. van Elp, J. Ghijsen, G.A. Sawatzky, and R.L. Johnson, Phys. Rev. B 41, 3190 (1990).

${ }^{8}$ G.B. Hoflund, Z.F. Hazos, and G.N. Salaita, Phys. Rev. B 62, 11126 (2000).

${ }^{9}$ J.F. Weaver and G.B. Hoflund, J. Phys. Chem. 98, 8519 (1994).

${ }^{10}$ K.T. Park, D.L. Novikov, V.A. Gubanov, and A.J. Freeman, Phys. Rev. B 49, 4425 (1994).

${ }^{11}$ A. Deb and A.K. Chatterjee, J. Phys. (France) 10, 11719 (1998).

${ }^{12}$ M.T. Czyzyk, R.A. de Groot, G. Dalba, P. Fornasini, A. Kisiel, F. Rocca, and E. Burattini, Phys. Rev. B 39, 9831 (1989).

${ }^{13}$ P. Villars and L. D. Calvert, Pearson's Handbook of Crystallographic Data for Intermetallic Phases (American Society for Metals, Metals Park, 1985), Vol. 1.

${ }^{14}$ E. Farhat and S. Robin-Kandare, Thin Solid Films 23, 315 (1974).

${ }^{15}$ E. Farhat, A. Donnadieu, and J. Robin, Thin Solid Films 29, 319 (1975).
${ }^{16}$ E. Farhat, A. Donnadieu, and J. Robin, Thin Solid Films 30, 83 (1975).

${ }^{17}$ R.A. Outlaw, D. Wu, M.R. Davidson, and G.B. Hoflund, J. Vac. Sci. Technol. A 10, 1497 (1992).

${ }^{18}$ A. Grill, Cold Plasma in Materials Fabrication (IEEE Press, New York, 1993).

${ }^{19}$ B. Chapman, Glow Discharge Processes (Wiley and Sons, New York, 1980).

${ }^{20}$ J.E. Klemberg-Spicher, O.M. Küttel, L. Martinu, and M.R. Wertheimer, Thin Solid Films 193/194, 965 (1990).

${ }^{21}$ N. N. Greenwood and A. Earnshaw, Chemistry of the Elements, 2nd ed. (Butterworth, London, 1997).

${ }^{22}$ J. Bohdansky, J. Roth, and H.L. Bay, J. Appl. Phys. 51, 2861 (1980).

${ }^{23}$ G. Carter and D.G. Armour, Thin Solid Films 80, 13 (1981).

${ }^{24}$ J. J. Yeh and I. Lindau, At. Data Nucl. Data Tables 32, (1985).

${ }^{25}$ P. Ruffieux, P. Schwaller, O. Gröning, L. Schlapbach, P. Gröning, Q.C. Herd, D. Funnemann, and J. Westermann, Rev. Sci. Instrum. 71, 3634 (2000).

${ }^{26} \mathrm{~S}$. Tanaka and T. Yamashina, J. Catal. 40, 140 (1975).

${ }^{27}$ A.I. Boronin, S.V. Koscheev, K.T. Murzakhmetov, V.I. Avdeev, and G.M. Zhidomirov, Astron. Astrophys., Suppl. Ser. 165, 9 (2000).

${ }^{28}$ W. L. Jolly, C. R. Brundle, and A. D. Baker, Electron Spectroscopy: Theory, Techniques and Applications (Academic, London, 1977), Vol. 1.

${ }^{29}$ W. Kohn and T.K. Ledd, Philos. Mag. 45, 313 (1982). 

